\title{
Long-wave infrared upconverter
}

Tseng, Yu Pei; Pedersen, Christian; Tidemand-Lichtenberg, Peter

Published in:

Mid-Infrared Coherent Sources, MICS 2018

Link to article, DOI:

10.1364/MICS.2018.MM4C.2

Publication date:

2018

Document Version

Peer reviewed version

Link back to DTU Orbit

Citation $(A P A)$ :

Tseng, Y. P., Pedersen, C., \& Tidemand-Lichtenberg, P. (2018). Long-wave infrared upconverter. In Mid-Infrared Coherent Sources, MICS 2018 [Paper MM4C.2] Optical Society of America (OSA). Optics InfoBase Conference Papers Vol. Part F87-MICS 2018 https://doi.org/10.1364/MICS.2018.MM4C.2

\section{General rights}

Copyright and moral rights for the publications made accessible in the public portal are retained by the authors and/or other copyright owners and it is a condition of accessing publications that users recognise and abide by the legal requirements associated with these rights.

- Users may download and print one copy of any publication from the public portal for the purpose of private study or research.

- You may not further distribute the material or use it for any profit-making activity or commercial gain

- You may freely distribute the URL identifying the publication in the public portal

If you believe that this document breaches copyright please contact us providing details, and we will remove access to the work immediately and investigate your claim. 


\title{
Long-wave Infrared Upconverter
}

\author{
Yu-Pei Tseng, Christian Pedersen, Peter Tidemand-Lichtenberg \\ DTU Fotonik, Technical University of Denmark, Frederiksborgvej 399, Roskilde 4000 \\ yupts@fotonik.dtu.dk
}

\begin{abstract}
An upconverter is demonstrated for long-wave infrared (LWIR) detection in a wide wavelength range, which can be potentially used for LWIR spectroscopy. The LWIR signal is mixed with a $1064 \mathrm{~nm}$ laser beam in a silver gallium sulfide $\left(\mathrm{AgGaS}_{2}\right)$ crystal using angle tuning for optimal phase-matching. This allows for efficient, high-speed detection of long-wave infrared signals using a standard silicon detector.

OCIS codes: (190.0190) Nonlinear Optics; (190.7220) Upconversion
\end{abstract}

\section{Introduction}

Many substances can be identified by their spectral features associated with fundamental rotational and vibrational absorption bands in the long-wave infrared spectral region. A variety of applications, such as infrared hyperspectral imaging [1,2] for medical applications and infrared spectroscopy [3,4] for instance used for environmental gas monitoring [5] and exhaled breath analysis [6] has attracted much attention. Throughout the past decades, significant scientific progress has led to new attractive mid-IR light sources, such as narrow band optical parametric oscillators [7] and quantum cascade lasers (QCL's) [8] driven by a demand from industrial applications.

However, direct LWIR detectors, such as Mercury cadmium telluride (MCT) detectors and bolometers, generally have poor signal-to-noise ratio, several orders of magnitude lower than that of silicon-based detectors, mainly due to its unavoidable dark noise originating from the finite temperature of the detector. Cooling is therefore required to optimize the performance of traditional LWIR detectors, but it generally makes them bulky and inconvenient to use. The response time of most IR detectors is generally much slower than their silicon detector counterparts. The lack of cheap, efficient detectors in the LWIR range has to some extent prevented widespread use of IR spectroscopy.

\section{Experiment}

An upconverter is demonstrated in this study showing how the IR radiation can be frequency converted via the nonlinear process of sum-frequency generation (SFG), which allows for the use of silicon detectors to acquire the upconverted signal [9]. Silver gallium sulfide $\left(\mathrm{AgGaS}_{2}\right)$ is the preferred nonlinear material in the 5 to $10 \mu \mathrm{m}$ range because of its high nonlinear coefficient of $d_{\text {eff }} \sim 13 \mathrm{pm} / \mathrm{V}$, broad transparency range from $550 \mathrm{~nm}$ to $12 \mu \mathrm{m}$, and being commercially available. The $\mathrm{AgGaS}_{2}$ crystal was cut at $\theta=43.3^{\circ}(\varphi=0)$ for type II phase-matching ( $\mathrm{e}_{\mathrm{LWIR}}+\mathrm{o}_{\text {pump }} \rightarrow$ $\left.\mathrm{e}_{\mathrm{NIR}}\right)$. The infrared source, for example a QCL laser, is mixed with a pump laser and focused into the nonlinear crystal for sum-frequency generation. Figure 1(a) shows the setup of the upconverter covering the range from 9 to $12 \mu \mathrm{m}$ by angular phase match tuning of the nonlinear material. The upconversion signal in the 956 to $977 \mathrm{~nm}$ range is detected using a silicon detector.

Direct detection of LWIR pulses has been challenging due to a slow rise time of MCT detectors. Upconversion allows for the use of silicon detectors typically having much faster response time. Figure 1(b) shows averaged oscilloscope traces of upconverted LWIR signals at $10.2 \mu \mathrm{m}$ with a pulse duration of $50 \mathrm{~ns}$. The upconverted signal is detected by a silicon avalanche photodiode (APD210, Thorlabs) having a rise time of $500 \mathrm{ps}$ and NEP $=0.4 \mathrm{pW} / \sqrt{\mathrm{Hz}}$. The average power of the LWIR signal is varied between 12.24 and $7.04 \mathrm{~mW}$, adjusting the QCL driving current. It should be noted that pulse shape is tilted due to the AC coupled mode of operation of the APD detector. Using a stable continuous wave laser for the upconversion process, the frequency conversion scheme does not add timing jitter nor amplitude fluctuations to the upconverted signals, hence, allowing for direct pulse characterization. 

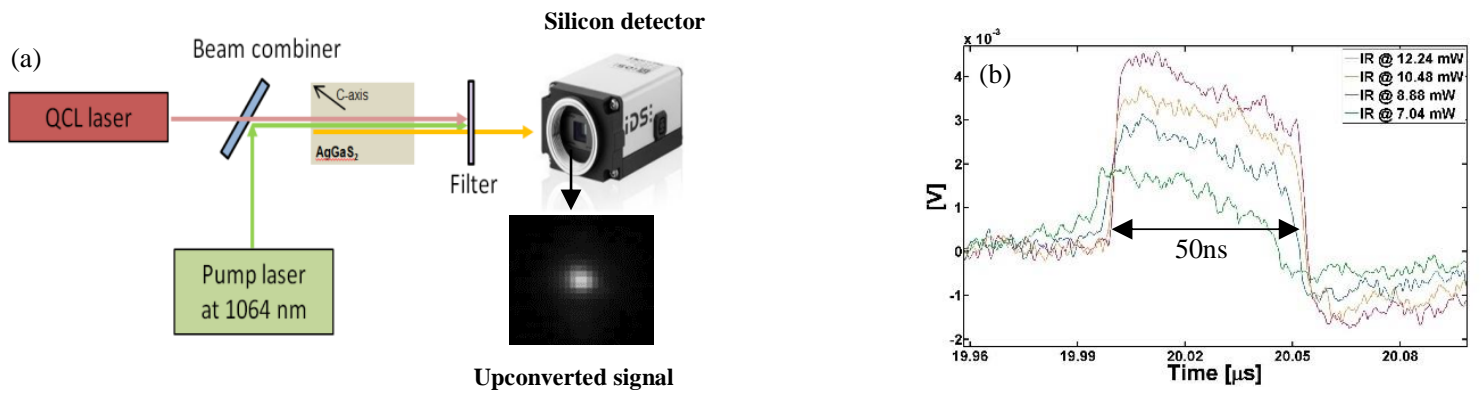

Fig. 1(a) Show the setup of upconverter and (b) Oscilloscope traces of upconverted signals, averaged by 10 sweeps, with a sampling rate of $5 \mathrm{GHz}$, at IR power of $7.04,8.88,10.48$, and $12.24 \mathrm{~mW}$ respectively.

\section{Conclusion}

In this study, we demonstrate upconversion detection for long-wave infrared sensing in a wide wavelength range proving it potential for LWIR spectroscopy using QCLs, potentially improving the signal-to-noise ratio, acquisition speed and applicability in real life applications. Long-wave infrared signals were successfully upconverted to the near infrared range allowing for detection using fast, efficient and low-noise silicon detectors. The fast acquisition time demonstrates the potential for real-time measurements.

\section{References}

[1] E. Normand, M. McCulloch, G. Duxbury, and N. Langford, "Fast, real-time spectrometer based on a pulsed quantum-cascade laser," Opt. Lett. 28(1), 16-18 (2003).

[2] D. D. Nelson, B. McManus, S. Urbanski, S. Herndon, and M. S. Zahniser, "High precision measurements of atmospheric nitrous oxide and methane using thermoelectrically cooled mid-infrared quantum cascade lasers and detectors," Spectrochim. Acta - Part A Mol. Biomol. Spectrosc. 60(14), 3325-3335 (2004). [3] F. Ladouceur and J. D. Love, Silica-based buried channel waveguides and devices (Chapman \& Hall, 1995), Chap. 8.

[3] R. W. Boyd and C. H. Townes, "An infrared upconverter for astronomical imaging," Appl. Phys. Lett. 31, 440-442 (1977).

[4] M. R. Kole, R. K. Reddy, M. V. Schulmerich, M. K. Gelber, and R. Bhargava, "Discrete Frequency Infrared Microspectroscopy and Imaging with a Tunable Quantum Cascade Laser," Anal. Chem. 84(23), 10366-10372 (2012).

[5] P. Ciais, C. Sabine, G. Bala, L. Bopp, V. Brovkin, J. Canadell, A. Chhabra, R. DeFries, J. Galloway, M. Heimann, C. Jones, C. Le Qu'er'e, R. B. Myneni, S. Piao, and P. Thornton, "2013: Carbon and Other Biogeochemical Cycles," in Climate Change 2013: The Physical Science Basis. Contribution of Working Group I to the Fifth Assessment Report of the Intergovernmental Panel on Climate Change, Stocker, T.F., D. Qin, G.-K. Plattner, M. Tignor, S.K. Allen, J. Boschung, A. Nauels, Y. Xia, V. Bex and P.M. Midgley (eds.) (Cambridge University, 2013).

[6] Y. Saalberg and M. Wolff, "VOC breath biomarkers in lung cancer," Clin. Chim. Acta 459, 5-9 (2016).

[7] S. C. Kumar, P. G. Schunemann, K. T. Zawilski, and M. Eberahim-Zadeh, "Advances in ultrafast optical parametric sources for the midinfrared based on CdSiP2," 33, 44-56 (2016).

[8] A. Hugi, R. Terazzi, Y. Bonetti, A. Wittmann, M. Fischer, M. Beck, J. Faist, and E. Gini, "External cavity quantum cascade laser tunable from 7.6 to $11.7 \mu \mathrm{m}, 2834,2007-2010(2009)$

[9] Y-P. Tseng, C. Pedersen, P. Tidemand-Lichtenberg, "'Upconversion detection of long-wave infrared radiation from a quantum cascade laser", Optical Express (to be submitted January 2018).

\section{Funding}

Mid-TECH H2020-MSCA-ITN-2014 Grant agreement no.: 64266 